\title{
Comparison of sleep quality, shoulder function, and quality of life in patients with different-sized rotator cuff tears
}

\author{
Ozge Vergili', Birhan Oktas ${ }^{2}$, Ibrahim Deniz Canbeyli ${ }^{3}$, Halime Arikan ${ }^{4}$, \\ Fatma Cansu Aktas Arslan ${ }^{5}$, \\ ${ }^{1}$ Assistant Professor, Department of Physiotherapy and Rehabilitation, Kırıkkale University, Faculty of Health Sciences, \\ Kirikkale, Turkey, ${ }^{2,3}$ Assistant Professor, Department of Orthopaedics and Traumatology, Kırıkkale University, Faculty \\ of Medicine, Kirikkale, Turkey, ${ }^{4}$ Assistant Professor, Department of Physiotherapy and Rehabilitation, Gazi University, \\ Faculty of Health Sciences, Ankara, Turkey, ${ }^{5}$ Assistant Professor, Department of Therapy and Rehabilitation, Sakarya \\ University of Applied Sciences, Sakarya, Turkey
}

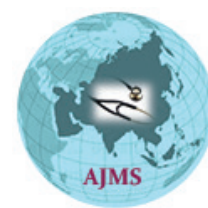

\section{A B S T R A C T}

Background: Many patients with rotator cuff tears suffer from nocturnal shoulder pain resulting in sleep disturbance, inability on shoulder function, and reduced quality of life. Aims and Objective: This study aimed to compare patients with different sizes of rotator cuff tears (RCTs) concerning sleep quality, shoulder function, quality of life, and emotional state. Materials and Methods: Forty-four patients (mean age 49.43 \pm 10.71 ) with different size of RCT were included in this prospective cross-sectional study. Patients were divided into two groups according to RCT size diagnosed with magnetic resonance imaging. Patients were evaluated with Pittsburgh Sleep Quality Index (PSQI), Constant Murley (CM) score, Western Ontario Rotator Cuff Index (WORC), and Beck Depression Inventory (BDI). Results: There was no significant difference between patients with small and large size RCT in terms of sleep quality, shoulder functionality, quality of life and emotional state $(p=0.841, p=0.258$, $p=0.916, p=0.936$, respectively). Conclusion: We demonstrated that patients with RCT had poor sleep quality, decreased shoulder function, poor quality of life, and normal emotional status, regardless of the tear size.

Key words: Mental status; Rotator cuff tears; Shoulder function; Sleep quality; Quality of life

Access this article online

Website:

http://nepjol.info/index.php/AJMS DOI: 10.3126/ajms.v12i8.36916

E-ISSN: 2091-0576

P-ISSN: 2467-9100

Copyright (c) 2021 Asian Journal of Medical Sciences

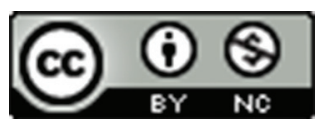

This work is licensed under a Creative Commons Attribution-NonCommercial 4.0 International License.

\section{INTRODUCTION}

Shoulder pain is one of the common musculoskeletal symptoms mainly caused by rotator cuff tears (RCTs). ${ }^{1}$ Clinically vast majority of patients with rotator cuff injuries suffer from pain, loss of strength, and impairment in normal shoulder function. ${ }^{2}$ Besides, sleep disturbance as a result of nocturnal pain is a major complaint of patients with rotator cuff tear. ${ }^{3}$ Nocturnal pain, insomnia, and a tendency to sleep as laying on the affected side are typically related to shoulder pathologies. ${ }^{3}$ Moreover, RCTs cause to sleep disturbances more than other shoulder disorders such as subacromial impingement and rotator cuff tendinopathies. ${ }^{4}$

It is well known that tear size affects healing and its clinical results. ${ }^{5}$ Therefore, sleep quality, shoulder functionality hence quality of life may be adversly affected by the size of rotator cuff tear. However, there is limited information available related to the tear size and sleep disturbance, ${ }^{2}$ shoulder function, ${ }^{6}$ and emotional state. ${ }^{7}$ Large-sized full-thickness RCT might impair sleep quality, shoulder functionality, emotional status, and quality of life (QOL) when compared with a small-sized tear. 
This study mainly aimed to evaluate sleep quality in patients with isolated full-thickness supraspinatus tendon tears in different sizes. Secondly, it is purposed to assess the shoulder function, emotional status, and QOL in these patients.

\section{MATERIALS AND METHODS}

This study was performed on 44 patients admitted to our orthopedics and traumatology department with a chief complaint of isolated sympthomatic supraspinatus tear with sleep disturbance. When a power analysis has been calculated, it is found that a sample size of at least 34 patients was designed based on a confidence interval of $95 \%$, power of $80 \%$. This research has been approved by the institutional review board of the authors' affiliated institutions (06.16.2017, dated and 17-KAEK-071, numdered). The study was conducted in accordance with the principles of the Declaration of Helsinki.

Patients with symptomatic isolated full-thickness supraspinatus tear confirmed on magnetic resonance imaging (MRI) and suffering from sleep disturbance were included in this prospective cohort study. Patients those who have undergone shoulder surgery, those who had any fracture involving the proximal humerus or shoulder, those who had an inflammatory joint disease, primary osteoarthritis, and adhesive capsulitis, those who had a documented history of psychotic disorder or glenohumeral joint dislocation were excluded from the study.

Associated data of patients regarding their sociodemographic characteristics, shoulder symptoms, functional status, emotional status, sleep quality, and QOL were collected via self-reported questionnaires included the Pittsburgh Sleep Quality Index (PSQI), Constant Murley (CM) score, Western Ontario Rotator Cuff Index (WORC), and Beck Depression Inventory (BDI) by a blind physiotherapist. All patients were informed on the methods and purpose of the study, and a written informed consent form was signed by patients.

Patients were categorized according to the size of supraspinatus tear by MRI findings. Size of rotator cuff tears of patients was defined by sagittal planes of the proton density (PD)-T2-weighted images $(\mathrm{MR} / \mathrm{tw})$ and classified according to actual size of full thickness RCT. Full-thickness tear types were classified as small tear $(<1 \mathrm{~cm})$; type 1 , a moderate tear $(1$ to $3 \mathrm{~cm})$; type 2 and a large/massive tear $(>3 \mathrm{~cm})$; type 3 lesions ${ }^{8}$. All patients were divided into two groups in order to limit the number of participants and make the sample more representative as follows;

Group 1: Patients with type 1 lesion (small tears)

Group 2: Patients with type 2 and 3 lesions (massive tears)

\section{Sleep quality}

Sleep quality was assessed with a reliable and valid questionnaire called the Pittsburgh Sleep Quality Index (PSQI) ${ }^{9}$. PSQI is a self-reported standardized questionnaire evaluating sleep disturbances and quality of sleep. It consists of 19 items and seven components. These components are composed of sleep disturbances, sleep duration, sleep latency, subjective sleep quality, habitual sleep efficiency, use of sleep medications, and day-time dysfunction. Each component is scored from 0 to 3 . High scores indicate more frequent sleep disturbances. The total PSQI score (ranging from 0 to 21) is obtained by the sum of the components. A five or higher PSQI score distinguish the patients with poor sleep quality with higher sensitivity (90-99\%) and specificity (84-87\%) ${ }^{9}$. The validity and reliability of PSQI was performed by Agargun et al. ${ }^{10}$.

\section{Shoulder function}

$\mathrm{CM}$ score provides an overall clinical functional assessment by recording individual parameters. The maximum $\mathrm{CM}$ score is 100 points and indicates excellent shoulder function. The original CM score has 4 subscales: range of motion (40 points), pain (15 points), activities of daily living (20 points), and strength (25 points) ${ }^{11}$. The visual analog scale (VAS) was used to scale pain ${ }^{12}$. Total Constant score is classified as excellent (90-100), good (80-89), moderate (70-79), and weak $(<70)^{13}$. The reliability and validity of the Turkish version of the modified CM score was performed by Celik et al. ${ }^{14}$.

\section{Quality of life}

The Western Ontario Rotator Cuff Index (WORC) is a 21 -item scale which is used to evaluate the QOL of patients with rotator cuff pathology. It has 6 questions for physical symptoms, 4 questions for work, 4 questions for sports and recreation, 3 questions for emotions, and 4 questions for lifestyle. Each question is scored with $100-\mathrm{mm}$ visual analog scale. The total score of 21 items changes between 0 and 2100. A score of 0 states no deterioration in QOL, and a score of 2,100 is the worst score for QOL ${ }^{15}$. The reliability and validity of the Turkish version of the WORC was performed by El et al. ${ }^{16}$.

\section{Emotional status}

Beck Depression Inventory (BDI) was used to evaluate the emotional status of individuals. BDI is an inventory that consists of 21 items. Each question is scored from 0 to 3. Total BDI score is classified as normal (0-9), mild depression (10-15), moderate depression (16-23), and 
severe depression (over 24 points) ${ }^{17}$. Turkish reliability and validity of BDI was performed by Hisli ${ }^{18}$.

\section{Statistical analysis}

Statistical Package for Social Sciences (SPSS) version 23.0 (IBM Corp., Armonk, NY, USA) for Windows was used for the statistical analysis of the research data. In the descriptive statistics section, categorical variables were presented as numbers, and percentages, and continuous variables as mean \pm standard deviation and median (minimum-maximum). Kolmogorov-Smirnov test was used to determine that the numeric variables were normally distributed. The Independent Samples t-Test and Mann Whitney $\mathrm{U}$ test were used to determine the differences between the two groups to compare means and medians. The Chi-Square test was used to determine the differences between the two groups to compare ratios. The $p$ values $<0.05$ were considered statistically significant, and all results were expressed with a $95 \%$ confidence interval.

\section{RESULTS}

Out of these patients, $52.3 \%$ were males $(\mathrm{n}=23)$ and $47.7 \%$ were females $(n=21)$. The mean age was $44.81 \pm 11.24$ (range, 22-66) in group 1, and 53.65 \pm 8.38 (range, 31-66) in group 2. The mean age was significantly higher in group $2(\mathrm{p}<0.005)$. Twenty-eight patients had right-sided involvement, while 16 patients had left-sided involvement. There was no significant difference between groups in terms of height, weight, body mass index, duration of complaints, and gender $(\mathrm{p}=0.818, \mathrm{p}=0.162, \mathrm{p}=0.231$, $\mathrm{p}=0.097$, and $\mathrm{p}=0.222$, respectively). Demographic characteristics of patients were summarized in Table 1.

\section{Sleep quality and depression}

All patients suffered from significant nocturnal pain. Sixteen $(36.3 \%)$ patients had PSQI scores higher than 5 while twenty-eight $(63.7 \%)$ patients had PSQI scores under 5. These high mean scores of PSQI in patients with RCT were remarkable; however, there were no significant differences between the two groups with regard to PSQI scores $(\mathrm{p}=0.841)$. Mean BDI scores of both groups were in normal range and there was no significant difference between groups $(\mathrm{p}=0.936)$. Details of mean PSQI scores with its' subgroups were given in Table 2.

\section{Shoulder function}

The mean CM score was $55.13 \pm 13.58$ in group 1 and $61.34 \pm 21.65$ in group 2. According to the constant score classification, both groups' mean CM score were scaled as weak. However, there was no significant difference between groups $(\mathrm{p}=0.258)$. Besides, the differences between the groups for each subgroup of $\mathrm{CM}$ score was also not significant. Details of the CM scores with its' subgroups are summarized in Table 3 .

\section{Quality of life}

The mean WORC score was $1158.10 \pm 283.77$ in group 1 and $1146.52 \pm 428.32$ in group 2 . There was no significant difference between groups in terms of WORC scores $(p=0.916)$. In addition, the differences between the groups for each subgroup of WORC was also not significant.

\begin{tabular}{|c|c|c|c|c|}
\hline & Group $1(n=21)$ & Group $2(n=23)$ & Total $(n=44)$ & $\mathbf{p}$ \\
\hline \multicolumn{5}{|l|}{ Age (year) } \\
\hline$X \pm S . D$ & $44.81 \pm 11.24$ & $53.65 \pm 8.38$ & $49.43 \pm 10.71$ & \multirow{3}{*}{$0.005^{* \alpha}$} \\
\hline Median & 46 & 55 & 51 & \\
\hline (Min.-Max) & $(22-66)$ & $(31-66)$ & $(22-66)$ & \\
\hline \multicolumn{5}{|l|}{ Height $(\mathrm{cm})$} \\
\hline X $\pm S . D$. & $166.48 \pm 7.39$ & $167.13 \pm 10.81$ & $166.82 \pm 9.24$ & \multirow{3}{*}{$0.818^{\alpha}$} \\
\hline Median & 165 & 170 & 167.50 & \\
\hline (Min.-Max) & $(148-180)$ & $(140-185)$ & $(140-185)$ & \\
\hline \multicolumn{5}{|l|}{ Weight (kg) } \\
\hline$X \pm S . D$. & $76.71 \pm 14.72$ & $83.65 \pm 17.36$ & $80.34 \pm 16.35$ & \multirow{3}{*}{$0.162^{\alpha}$} \\
\hline Median & 78 & 81 & 80 & \\
\hline (Min.-Max) & $(48-118)$ & $(53-115)$ & $(48-118)$ & \\
\hline \multicolumn{5}{|l|}{ BMI $\left(\mathrm{kg} / \mathrm{m}^{2}\right)$} \\
\hline X \pm S.D. & $27.77 \pm 5.62$ & $30.20 \pm 7.45$ & $29.04 \pm 6.68$ & \multirow{3}{*}{$0.231^{a}$} \\
\hline Median & 27.78 & 28.37 & 28.06 & \\
\hline (Min.-Max) & $(17.63-43.87)$ & $(18.78-51.11)$ & $(17.63-51.11)$ & \\
\hline \multicolumn{5}{|c|}{ Duration of complaint (month) } \\
\hline X士S.D. & $10.29 \pm 11.42$ & $16.96 \pm 16.72$ & $13.77 \pm 14.66$ & \multirow{3}{*}{$0.097^{\beta}$} \\
\hline Median & 7 & 12 & 8 & \\
\hline (Min.-Max) & $(2-48)$ & $(2-60)$ & $(2-60)$ & \\
\hline \multicolumn{5}{|l|}{ Gender n (\%) } \\
\hline Female & $13(29.5 \%)$ & $10(22.7 \%)$ & $23(52.3 \%)$ & \multirow[t]{2}{*}{$0.222^{\mu}$} \\
\hline Male & $8(18.2 \%)$ & $13(29.5 \%)$ & $21(47.7 \%)$ & \\
\hline
\end{tabular}




\begin{tabular}{|c|c|c|c|c|}
\hline & Group $1(n=21)$ & Group $2(n=23)$ & Total $(n=44)$ & $p$ \\
\hline \multicolumn{5}{|l|}{ PSQI } \\
\hline 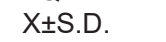 & $7.90 \pm 3.94$ & $7.48 \pm 3.37$ & $7.68 \pm 3.61$ & \multirow{3}{*}{$0.841^{\beta}$} \\
\hline Median & 7 & 7 & 7 & \\
\hline (Min.-Max) & $(4-15)$ & $(2-14)$ & $(2-15)$ & \\
\hline \multicolumn{5}{|l|}{ Sleep quality } \\
\hline$X \pm S . D$. & $1.52 \pm 0.87$ & $1.26 \pm 0.81$ & $1.39 \pm 0.84$ & \multirow{3}{*}{$0.346^{\beta}$} \\
\hline Median & 1 & 1 & 1 & \\
\hline (Min.-Max) & $(0-3)$ & $(0-3)$ & $(0-3)$ & \\
\hline \multicolumn{5}{|l|}{ Sleep latency } \\
\hline$X \pm S . D$. & $1.24 \pm 1.14$ & $1.13 \pm 1.06$ & $1.18 \pm 1.08$ & \multirow{3}{*}{$0.769^{\beta}$} \\
\hline Median & 1 & 1 & 1 & \\
\hline (Min.-Max) & $(0-3)$ & $(0-3)$ & $(0-3)$ & \\
\hline \multicolumn{5}{|c|}{ Sleep duration } \\
\hline$X \pm S . D$. & $1.33 \pm 0.91$ & $1.74 \pm 0.96$ & $1.55 \pm 0.95$ & \multirow{3}{*}{$0.162^{\beta}$} \\
\hline Median & 2 & 2 & 2 & \\
\hline (Min.-Max) & $(0-3)$ & $(0-3)$ & $(0-3)$ & \\
\hline \multicolumn{5}{|c|}{ Habitual sleep efficiency } \\
\hline$X \pm S . D$. & $0.81 \pm 1.17$ & $0.91 \pm 1.16$ & $0.86 \pm 1.15$ & \multirow{3}{*}{$0.736^{\beta}$} \\
\hline Median & 0 & 0 & 0 & \\
\hline (Min.-Max) & $(0-3)$ & $(0-3)$ & $(0-3)$ & \\
\hline \multicolumn{5}{|c|}{ Sleep disturbances } \\
\hline$X \pm S . D$. & $1.71 \pm 0.72$ & $1.78 \pm 0.67$ & $1.75 \pm 0.69$ & \multirow{3}{*}{$0.699^{\beta}$} \\
\hline Median & 2 & 2 & 2 & \\
\hline (Min.-Max) & $(1-3)$ & $(1-3)$ & $(1-3)$ & \\
\hline \multicolumn{5}{|c|}{ Use of sleep medications } \\
\hline X $\pm S . D$. & $0.19 \pm 0.68$ & $0 \pm 0$ & $0.09 \pm 0.47$ & \multirow{3}{*}{$0.134^{\beta}$} \\
\hline Median & 0 & 0 & 0 & \\
\hline (Min.-Max) & $(0-3)$ & $(0-0)$ & $(0-3)$ & \\
\hline \multicolumn{5}{|c|}{ Day time dysfunction } \\
\hline$X \pm S . D$. & $1.10 \pm 1.04$ & $0.65 \pm 0.98$ & $0.86 \pm 1.03$ & \multirow{3}{*}{$0.120^{\beta}$} \\
\hline Median & 1 & 0 & 0 & \\
\hline (Min.-Max) & $(0-3)$ & $(0-3)$ & $(0-3)$ & \\
\hline \multicolumn{5}{|l|}{$\mathrm{BDI}$} \\
\hline X土S.D. & $9.33 \pm 6.73$ & $9.48 \pm 5.04$ & $9.41 \pm 5.84$ & \multirow{3}{*}{$0.936^{\alpha}$} \\
\hline Median & 8 & 9 & 9 & \\
\hline (Min.-Max) & $(0-24)$ & $(1-19)$ & $(0-24)$ & \\
\hline
\end{tabular}

(PSOI: Pittsburg Sleep Quality Index; BDI: Beck Depression Inventory; X: Mean; S.D.: Standard deviation; Min.: Minimum; Max.: Maximum; $\alpha$ : Independent Samples t Test; $\beta$ : Mann Whitney u Test)

Details of WORC scores with its' subgroups were summarized in Table 4.

\section{DISCUSSION}

Rotator cuff tear (RCT) has always preserved its' importance due to it may be responsible for, loss of strength, shoulder disability, reduced sleep quality, and decreased quality of life. ${ }^{19}$ Sleep disturbance, which involves $15 \%$ to $35 \%$ of the general population, ${ }^{20}$ is a medical disorder of the sleep patterns that may seriously affect a patients' life quality and may cause mood disorders and anxiety. ${ }^{4,21}$ In our study, patients with small and large rotator cuff tears suffered from severe nocturnal shoulder pain and sleep disturbance. The most important result of this study was that while rotator cuff tears caused a significant decrease in sleep quality, shoulder function, and quality of life, there was no correlation between tear size and sleep quality, shoulder function, emotional status, and quality of life.
Reyes et al., ${ }^{22}$ reported a large cross-sectional study of 209 patients with symptomatic full-thickness rotator cuff tear. The authors stated that patients with massive rotator cuff tear had more decrease in shoulder functions; however, there was no correlation between rotator cuff tear characteristics such as size and retraction of tendon and sleep disturbance. In another study, Curry et al. ${ }^{23}$ concluded that size of rotator cuff tear was not associated with increased shoulder pain. In the current study, although, the difference between groups was not statistically significant, and it was likely of no clinical importance, patients with large tears had a little bit better PSQI scores than those with small tears. In contrast, Gumina et al., ${ }^{19}$ observed that patients with a small tear had significantly better sleep quality than those with large tears in their study with enrolled 324 consecutive patients. This difference may be related to the patients with small tears are more susceptible to shoulder pain due to small tears often having a greater amount of inflamed bursal tissue than large tears. ${ }^{24}$ In addition, the prolonged stimuli acting on the nociceptors located on the edges of large tears may undergo receptor 


\begin{tabular}{|c|c|c|c|c|}
\hline & Group $1(n=21)$ & Group $2(n=23)$ & Total $(n=44)$ & $p$ \\
\hline \multicolumn{5}{|l|}{ CM score } \\
\hline$X \pm S . D$. & $55.13 \pm 13.58$ & $61.34 \pm 21.65$ & $58.38 \pm 18.31$ & \multirow{3}{*}{$0.258^{\alpha}$} \\
\hline Median & 55.56 & 62.38 & 58.11 & \\
\hline (Min.-Max) & (29.44-79.33) & $(21.89-94.22)$ & $(21.89-94.22)$ & \\
\hline \multicolumn{5}{|l|}{ Pain score } \\
\hline X \pm S.D. & $4.67 \pm 3.92$ & $5.52 \pm 4.02$ & $5.11 \pm 3.95$ & \multirow{3}{*}{$0.336^{\beta}$} \\
\hline Median & 5 & 5 & 5 & \\
\hline (Min.-Max) & $(0-13)$ & $(0-13)$ & $(0-13)$ & \\
\hline \multicolumn{5}{|c|}{ Functional assessment } \\
\hline$X \pm S . D$. & $13.48 \pm 3.04$ & $13.78 \pm 4.27$ & $13.64 \pm 3.70$ & \multirow{3}{*}{$0.344^{\beta}$} \\
\hline Median & 13 & 14 & 13.5 & \\
\hline (Min.-Max) & $(5-19)$ & $(1-20)$ & $(1-20)$ & \\
\hline \multicolumn{5}{|c|}{ Range of motion } \\
\hline$X \pm S . D$. & $27.33 \pm 7.41$ & $29.91 \pm 9.35$ & $28.68 \pm 8.48$ & \multirow{3}{*}{$0.319^{\alpha}$} \\
\hline Median & 30 & 34 & 30 & \\
\hline (Min.-Max) & $(14-40)$ & $(10-40)$ & $(10-40)$ & \\
\hline \multicolumn{5}{|c|}{ Strength measures } \\
\hline$X \pm S . D$. & $9.66 \pm 5.01$ & $12.12 \pm 9.02$ & $10.94 \pm 7.41$ & \multirow{3}{*}{$0.533^{\beta}$} \\
\hline Median & 8.67 & 10.44 & 9.56 & \\
\hline (Min.-Max) & $(2.44-21.33)$ & $(0-28.98)$ & $(0-28.98)$ & \\
\hline
\end{tabular}

Table 4: Comparison of quality of life of the groups via Western Ontario Rotator Cuff Index

\begin{tabular}{|c|c|c|c|c|}
\hline & Group $1(n=21)$ & Group $2(n=23)$ & Total $(n=44)$ & $\mathbf{p}$ \\
\hline \multicolumn{5}{|l|}{ WORC } \\
\hline X士S.D. & $1158.10 \pm 283.77$ & $1146.52 \pm 428.32$ & $1152.05 \pm 362.42$ & \multirow{3}{*}{$0.916^{a}$} \\
\hline Median & 1160 & 1190 & 1175 & \\
\hline (Min.-Max) & $(640-1680)$ & $(390-1850)$ & $(390-1850)$ & \\
\hline \multicolumn{5}{|c|}{ Physical function } \\
\hline X $\pm S . D$. & $308.57 \pm 87.82$ & $311.52 \pm 101.15$ & $310.11 \pm 93.94$ & \multirow{3}{*}{$0.919^{a}$} \\
\hline Median & 340 & 300 & 320 & \\
\hline (Min.-Max) & $(100-450)$ & $(140-510)$ & $(100-510)$ & \\
\hline \multicolumn{5}{|c|}{ Sports recreation } \\
\hline X $\pm S . D$. & $265.24 \pm 62.50$ & $246.30 \pm 89.93$ & $255.34 \pm 77.75$ & \multirow{3}{*}{$0.671^{\beta}$} \\
\hline Median & 270 & 270 & 270 & \\
\hline (Min.-Max) & $(100-340)$ & $(50-360)$ & $(50-360)$ & \\
\hline \multicolumn{5}{|l|}{ Work } \\
\hline X士S.D. & $234.76 \pm 79.41$ & $238.04 \pm 94.25$ & $236.48 \pm 86.49$ & \multirow{3}{*}{$0.902^{a}$} \\
\hline Median & 250 & 260 & 255 & \\
\hline (Min.-Max) & $(80-370)$ & $(80-360)$ & $(80-370)$ & \\
\hline \multicolumn{5}{|l|}{ Lifestyle } \\
\hline X土S.D. & $218.57 \pm 86.56$ & $208.91 \pm 109.71$ & $213.52 \pm 98.32$ & \multirow{3}{*}{$0.749^{a}$} \\
\hline Median & 210 & 200 & 205 & \\
\hline (Min.-Max) & $(30-370)$ & $(40-390)$ & $(30-390)$ & \\
\hline \multicolumn{5}{|l|}{ Emotions } \\
\hline X土S.D. & $130.95 \pm 73.41$ & $141.74 \pm 94.56$ & $136.59 \pm 84.33$ & \multirow{3}{*}{$0.677^{\circ}$} \\
\hline Median & 120 & 150 & 125 & \\
\hline (Min.-Max) & $(30-290)$ & $(30-290)$ & $(30-290)$ & \\
\hline
\end{tabular}

adaptation that may lead to a lower intensity of shoulder pain in patients with large RCT. There is still a need for more large-scale studies to reveal the effect of tear size on shoulder pain and sleep quality.

Rotator cuff tears may cause shoulder pain and decrease in shoulder function; hence low life quality. It was well documented that quality of life was negatively affected in patients with RCT. ${ }^{25,26}$ Löhteenmaki et al., ${ }^{27}$ evaluated shoulder function in 246 patients with a full-thickness
RCT. The authors reported that patients with small size tears had slightly better functions than medium-sized and massive tears. However, this difference was not statistically significant. Similarly, McCabe et al., ${ }^{6}$ reported a decrease in overall shoulder function, and there was also no significant difference between patients with small and large-sized RCT. In the current study, patients had a poor quality of life and decreased shoulder functions in both groups. However, there was no statistically significant difference between patients with small and large-sized RCT regarding shoulder 
functionality and quality of life. These results underlined that quality of life and shoulder functions may be decreased by RCT regardless of tear size.

Mental status is another main problem to consider in patients with RCT. Wylie et al., evaluated whether mental health or tear size were strongly associated with shoulder pain and function. They underlined patients' mental status may play an influential role in patients with rotator cuff tear. However, in the current study, depression levels of patients with RCT were in the normal range. In addition, there was also no significant difference between patients with small and large RCTs regarding depression. We considered that this difference might be a result of the similar shoulder pain scores of both groups. The somatic symptoms such as joint pain and low back pain play a significant role in developing depression due to the relationship between psychological and physical conditions. ${ }^{28,29}$ Thus, there may not be an emotional difference between groups since there was no functional difference caused by the shoulder pain. Further large-scale studies are needed to determine the relationship between emotional state, tear size and shoulder pain.

This study has some limitations. The main limitation was the lack of a control group, which consist of patients without RCT. This issue should be considered in further studies to define the differences between patients with and without RCT regarding sleep quality, shoulder function, quality of life, and emotional status. Secondly, potential possible co-morbid desaeses may cause sleep disturbance such as prostatic hyperplasia, neurological diseases, and hypertension were not considered in detail. ${ }^{19}$ Besides, sleeping habits may differ among individuals. Finally, patients with long-term shoulder pain may have developed a state of anxiety and depression that may affect responses to the questionnaires. ${ }^{30}$

\section{CONCLUSIONS}

In our study, the tear size does not correlate with shoulder functionality, sleep quality, or mental status in direct proportion. All variable size of rotator cuff tears is capable of decreasing patients' sleep quality and functional capacity without any alteration psychological status. It must keep in mind that patients' functional and psychological complaints may not directly represent a small-sized or massive tear; however, cuff tears may directly be associated with sleep quality.

\section{REFERENCES}

1. Gomoll AH, Katz JN, Warner JJ and Millett PJ. Rotator cuff disorders: recognition and management among patients with shoulder pain. Arthritis and rheumatism. 2004; 50:3751-3761. 1462.

https://doi.org/10.1002/art.20668

2. Gumina S, Candela V, Passaretti D, Venditto T, Carbone S, Arceri V, et al. Intensity and distribution of shoulder pain in patients with different sized postero-superior rotator cuff tears. J Shoulder Elbow Surg. 2014; 23:807-813.

https://doi.org/10.1016/j.jse.2013.09.011

3. Tekeoglu I, Ediz L, Hiz O, Toprak M, Yazmalar L and Karaaslan G. The relationship between shoulder impingement syndrome and sleep quality. Eur Rev Med Pharmacol Sci. 2013; 17:370-374.

4. Khazzam MS, Mulligan EP, Brunette-Christiansen $M$ and Shirley Z. Sleep Quality in Patients With Rotator Cuff Disease. J Am Acad Orthop Surg. 2018; 26:215-222. https://doi.org/10.5435/JAAOS-D-16-00547

5. Fuchs B, Gilbart MK, Hodler J and Gerber C. Clinical and structural results of open repair of an isolated one-tendon tear of the rotator cuff. The Journal of Bone and Joint Surgery. 2006; 88:309-316.

https://doi.org/10.2106/JBJS.E.00117

6. McCabe RA, Nicholas SJ, Montgomery KD, Finneran JJ and McHugh MP. The effect of rotator cuff tear size on shoulder strength and range of motion. J Orthop Sports Phys Ther. 2005; 35:130-135.

https://doi.org/10.2519/jospt.2005.35.3.130

7. Wylie JD, Suter T, Potter MQ, Granger EK and Tashjian RZ. Mental Health Has a Stronger Association with Patient-Reported Shoulder Pain and Function Than Tear Size in Patients with Full-Thickness Rotator Cuff Tear. J Bone Joint Surg Am. 2016; 98:251-256.

https://doi.org/10.2106/JBJS.0.00444

8. Al-Shawi A, Badge $\mathrm{R}$ and Bunker T. The detection of full thickness rotator cuff tears using ultrasound. J Bone Joint Surg [Br]. 2008; 90:889-892.

https://doi.org/10.1302/0301-620X.90B7.20481

9. Carpenter JS and Andrykowski MA. Psychometric evaluation of the Pittsburgh sleep quality index. Journal of psychosomatic research. 1998; 45:5-13.

https://doi.org/10.1016/S0022-3999(97)00298-5

10. Agargün MY, Kara $\mathrm{H}$ and Anlar Ö. The validity and reliability of the Pittsburgh Sleep Quality Index. Turk Psikiyatri Derg. 1996; 7:107-115.

11. Constant $\mathrm{C}$ and Murley A. A clinical method of functional assessment of the shoulder. Clinical orthopaedics and related research. 1987; 214:160-164.

https://doi.org/10.1097/00003086-198701000-00023

12. Constant CR, Gerber C, Emery RJH, Søjbjerg JO, Gohlke F and Boileau P. A review of the Constant score: modifications and guidelines for its use. J Shoulder Elbow Surg. 2008; 17:355-361. https://doi.org/10.1016/j.jse.2007.06.022

13. Ekin A and Ozcan C. Massive rotator cuff tears: diagnosis and treatment techniques. Acta Orthop Traumatol Turc. 2003; 37:87-92.

14. Celik D. Turkish version of the modified Constant-Murley score and standardized test protocol: reliability and validity. Acta Orthop Traumatol Turc. 2016; 50:69-75. https://doi.org/10.3944/AOTT.2016.14.0354

15. Kirkley A, Griffin S, McLintock $\mathrm{H}$ and $\mathrm{Ng} \mathrm{L}$. The development and evaluation of a disease-specific quality of life measurement tool for shoulder instability. The American Journal of Sports Medicine. 1998; 26:764-772.

https://doi.org/10.1177/03635465980260060501

16. El O, Bircan C, Gulbahar S, Demiral Y, Sahin E, Baydar M, et al. 
The reliability and validity of the Turkish version of the Western Ontario Rotator Cuff Index. Rheumatology international. 2006; 26:1101-1108.

https://doi.org/10.1007/s00296-006-0151-2

17. Beck AT, Steer RA and Garbin MG. Psychometric properties of the Beck Depression Inventory: Twenty-five years of evaluation. Clin Psychol Rev. 1988; 8:77-100.

https://doi.org/10.1016/0272-7358(88)90050-5

18. Hisli N. A reliability and validity study of Beck Depression Inventory in a university student sample. J Psychol. 1989; 7:3-13.

19. Gumina S, Candela V, Passaretti D, Venditto $T$, Mariani $L$ and Giannicola G. Sleep quality and disturbances in patients with different-sized rotator cuff tear. Musculoskelet Surg. 2016; 100:33-38.

https://doi.org/10.1007/s12306-016-0405-4

20. Austin L, Pepe M, Tucker B, Ong A, Nugent R, Eck B, et al. Sleep disturbance associated with rotator cuff tear: correction with arthroscopic rotator cuff repair. Am J Sports Med. 2015; 43:1455-1459.

https://doi.org/10.1177/0363546515572769

21. Mulligan EP, Brunette $M$, Shirley $Z$ and Khazzam M. Sleep quality and nocturnal pain in patients with shoulder disorders. J Shoulder Elbow Surg. 2015; 24:1452-1457.

https://doi.org/10.1016/j.jse.2015.02.013

22. Reyes BA, Hull BR, Kurth AB, Kukowski NR, Mulligan EP and Khazzam MS. Do Magnetic Resonance Imaging Characteristics of Full-Thickness Rotator Cuff Tears Correlate With Sleep Disturbance? Orthop J Sports Med. 2017; 5:2325967117735319. https://doi.org/10.1177/2325967117735319

23. Curry EJ, Matzkin EE, Dong Y, Higgins LD, Katz JN and Jain NB. Structural Characteristics Are Not Associated With Pain and Function in Rotator Cuff Tears: The ROW Cohort Study. Orthop J Sports Med. 2015; 3:2325967115584596.

https://doi.org/10.1177/2325967115584596
24. Gumina S, Natalizi S, Melaragni F, Leopizzi M, Carbone S, Postacchini $F$, et al. The possible role of the transcription factor nuclear factor-kappaB on evolution of rotator cuff tear and on mechanisms of cuff tendon healing. J Shoulder Elbow Surg. 2013; 22:673-680. https://doi.org/10.1016/j.jse.2012.06.005

25. Ekeberg OM, Bautz-Holter E, Keller A, Tveita EK, Juel NG and Brox JI. A questionnaire found disease-specific WORC index is not more responsive than SPADI and OSS in rotator cuff disease. J Clin Epidemiol. 2010; 63:575-584. https://doi.org/10.1016/j.jclinepi.2009.07.012

26. de Witte PB, Henseler JF, Nagels J, Vliet Vlieland TP and Nelissen RG. The Western Ontario rotator cuff index in rotator cuff disease patients: a comprehensive reliability and responsiveness validation study. Am J Sports Med. 2012; 40:1611-1619.

https://doi.org/10.1177/0363546512446591

27. Lahteenmaki HE, Hiltunen A, Virolainen $P$ and Nelimarkka $O$. Repair of full-thickness rotator cuff tears is recommended regardless of tear size and age: a retrospective study of 218 patients. J Shoulder Elbow Surg. 2007; 16:586-590. https://doi.org/10.1016/j.jse.2007.04.001

28. Hein S, Bonsignore M, Barkow K, Jessen F, Ptok U and Heun R. Lifetime depressive and somatic symptoms as preclinical markers of late-onset depression. European archives of psychiatry and clinical neuroscience. 2003; 253:16-21. https://doi.org/10.1007/s00406-003-0399-4

29. Nakao $M$ and Yano E. Somatic symptoms for predicting depression: One-year follow-up study in annual health examinations. Psychiatry and clinical neurosciences. 2006; 60:219-225. https://doi.org/10.1111/j.1440-1819.2006.01489.x

30. Badcock LJ, Lewis M, Hay EM, McCarney R and Croft PR. Chronic shoulder pain in the community: a syndrome of disability or distress? Ann Rheum Dis. 2002; 61:128-131. https://doi.org/10.1136/ard.61.2.128

\section{Author's Contribution:}

OV,IDC - Concept and design of the study; prepared first draft of manuscript; BO - Interpreted the results; reviewed the literature and manuscript preparation; HA, IDC - Concept, coordination, review of literature and manuscript preparation; FCAA - Statistically analysed and interpreted, preparation of manuscript and revision of the manuscript.

Work attributed to:

Kırıkkale University Hospital, Kirikkale, Turkey.

Orcid ID:

Dr. Ozge Vergili - (i) https://orcid.org/0000-0002-5312-7684

Dr. Birhan Oktas - io https://orcid.org/0000-0003-4859-5616

Dr. Ibrahim Deniz Canbeyli - (D) https://orcid.org/0000-0003-3880-4779

Dr. Halime Arikan - (i) https://orcid.org/0000-0003-2381-9978

Dr. Fatma Cansu Aktas Arslan - (1) https://orcid.org/0000-0002-9233-6542

Source of Funding: None, Conflict of Interest: None. 